Article

\title{
Synthesis and Properties of a Chiroptically Active Oligomer from 3,4-Ethylenedioxythiophene and (-)-Myrtenal
}

\section{Hirotsugu Kawashima and Hiromasa Goto *}

Institute of Materials Science, Graduate School of Pure and Applied Sciences, University of Tsukuba, Tsukuba, Ibaraki 305-8573, Japan; E-Mail: s-hkawashima@ims.tsukuba.ac.jp

* Author to whom correspondence should be addressed; E-Mail: gotoh @ims.tsukuba.ac.jp; Tel.: +81-29-853-5128; Fax: +81-29-853-4490.

Received: 23 March 2011; in revised form: 29 April 2011 / Accepted: 27 May 2011 /

Published: 30 May 2011

\begin{abstract}
Oxidative polycondensation of 3,4-ethylenedioxythiophene and (-)-myrtenal was carried out with $\mathrm{POCl}_{3}$. A $\pi$-conjugated system thus constructed consists of aromatic and quinoidal alternating structure linked via methine groups. We examined iodine doping effect for the resultant material with electron spin resonance spectroscopy. Circular dichroism spectra in chloroform solution showed blue-shift with increase of iodine concentration. This result indicates that the doping process can tune chiroptical activity of the chiral $\pi$-conjugated system.
\end{abstract}

Keywords: poly(3,4-ethylenedioxythiophene); chiroptically active materials; $\pi$-conjugated materials

\section{Introduction}

Many kinds of conjugated polymers have been widely studied for applications, such as transparent conductors, light-emitting diodes, thin film transistors, and photovoltaic devices [1-9]. Low-bandgap conjugated polymer is of interest because of its sensitivity in optical and electrical impulsions for external stimuli [10-14]. Poly(3,4-ethylenedioxythiophene) (PEDOT) and its derivatives are widely studied conjugated polymers due to their relatively low ionization potential, high electrical conductivity, and good stability [15-20]. A conjugated polymer which has benzenoid and quinonoid alternating structure in the main chain bridged via methine group (methine polymer) has been paid much attention because of the relatively small-bandgap [21-27]. Polycondensation between arylene 
unit and aldehyde group in the presence of sulfuric acid has been developed [28,29]. The polymerization is shown in Scheme 1. We synthesized a methine oligomer (abbreviated as ME1) from EDOT and (-)-myrtenal, a chiral compound (Scheme 2). Chiroptical activity and doping effect for the resultant thus prepared is examined based on consideration of high sensitivity derived from low-bandgap.

Scheme 1. Dehydrative polycondensation for methine type polymer.

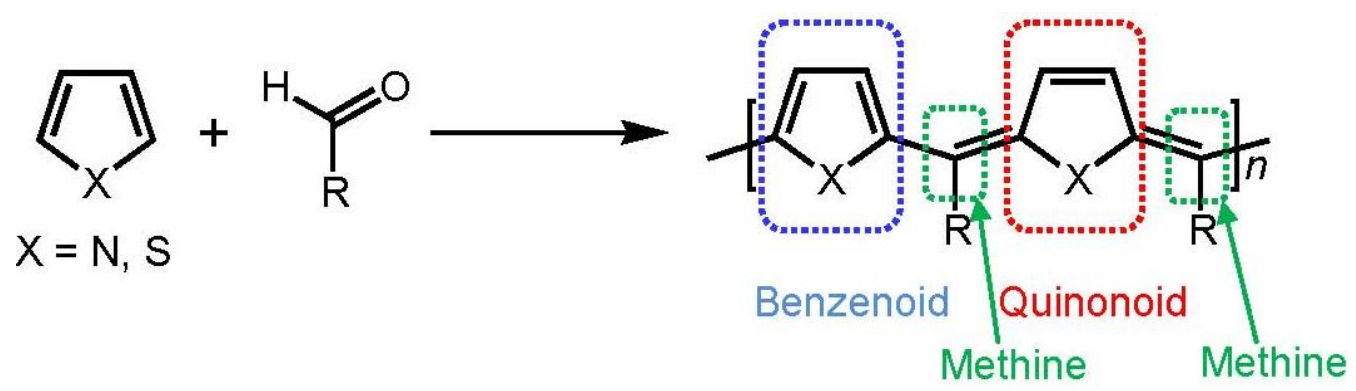

\section{Experimental Section}

Polycondensation between aldehydes and thiophenes provides Novolac-type polymers [30]. In this reaction, the protonated aldehyde electrophile can sequentially react with active site ( $\alpha, \alpha^{\prime}$-position) of thiophene. Chen and Jenekhe proved following elimination of protons at methine linkages by sulfuric acid for producing full $\pi$-conjugated skeleton [29].

Polycondensation of pyrrole and 1-dodecanal was carried out for obtaining polypyrrole-methine type $\pi$-conjugated polymers [31]. The Rothemund type reaction for synthesis of porphyrine can be applied for polycondensation between EDOT and chiral aldehydes for construction of $\pi$-conjugated main chain [32,33]. In this case, bulky group in the substituents can prevent a formation of cyclic compounds.

Scheme 2. Synthesis of methine bridged oligomer as a main product from 3,4-ethylenedioxythiophene (EDOT) and (-)-myrtenal.

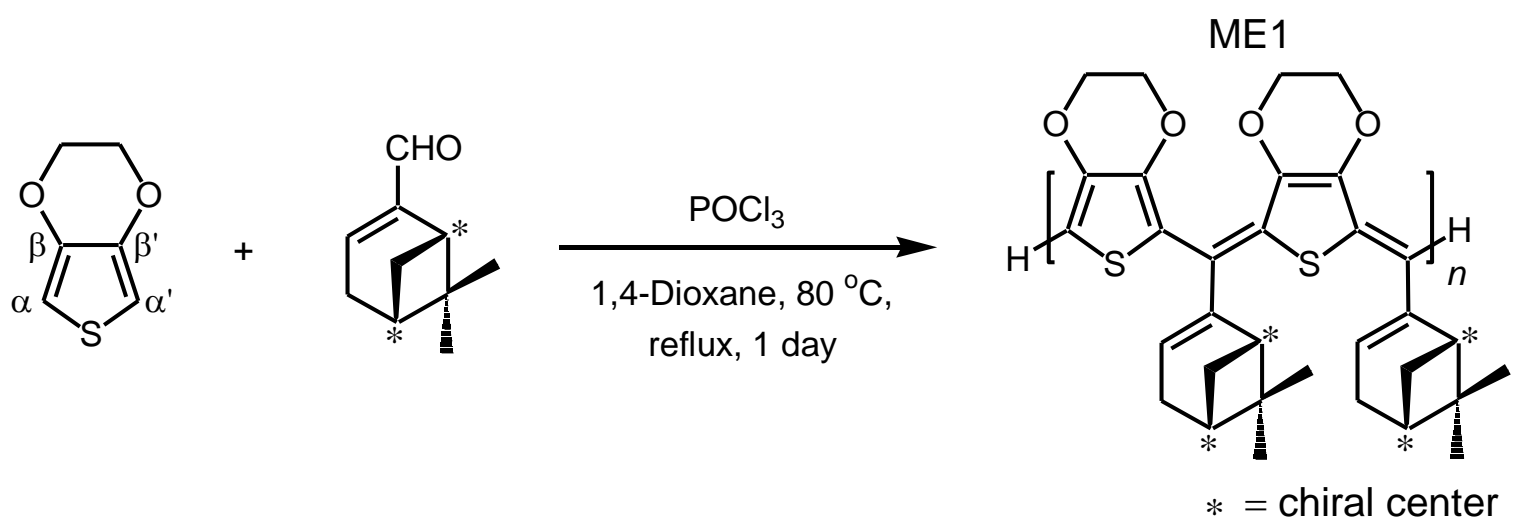

Chemicals were purchased from Tokyo Kasei and Aldrich and used as received. ${ }^{1} \mathrm{H}$ NMR measurements of (-)-myrtenal and ME1 were performed in $\mathrm{CDCl}_{3}$ with $\mathrm{ECS} 400$ spectrometer (JEOL) at room temperature. Chemical shifts are reported in ppm downfield from $\mathrm{SiMe}_{4}$, using the solvent's residual signal as an internal reference. Fourier transfer infrared (FTIR) absorption spectra of ME1 and 
(-)-myrtenal were obtained by FT/IR-300 spectrometer (Jasco), with the KBr method. Molecular weights of ME1 were determined by gel permeation chromatography (GPC) with MIXED-D HPLC column (Polymer Laboratories), PU-980 HPLC pump (Jasco) and MD-915 multiwavelength detector (Jasco), with THF used as the solvent, with the instruments calibrated by polystyrene standard. UVvisible absorption spectra were recorded on V-630 UV-vis optical absorption spectrometer (Jasco). Circular dichroism (CD) spectra were obtained with J-720 spectrometer (Jasco). Electron spin resonance (ESR) spectra were taken at room temperature using JES-TE200 ESR spectrometer (JEOL) during in-situ vapor phase doping process with iodine.

The target material was synthesized by dehydrative polycondensation between EDOT and (-)-myrtenal with $\mathrm{POCl}_{3}$. The reaction was carried out in a Schlenk tube.

A solution of EDOT $(0.50 \mathrm{~g}, 3.5 \mathrm{mmol}),(-)$-myrtenal $(0.54 \mathrm{~g}, 3.6 \mathrm{mmol})$, and $\mathrm{POCl}_{3}(0.061 \mathrm{~g}$, $0.40 \mathrm{mmol}$ ) in 1,4-dioxane $\left(5 \mathrm{~mL}\right.$ ) was refluxed at $80{ }^{\circ} \mathrm{C}$ for $25 \mathrm{~h}$ (molecular structure of EDOT and $(-)$-myrtenal are shown in Scheme 2). The reaction mixture was poured into a large amount of methanol. Then, aqueous ammonia was added to remove the catalyst from the resultant. The crude product was purified by several washes in methanol. The precipitate was filtered off and dried under reduced pressure to yield the desired compound as a brown color solid. ${ }^{1} \mathrm{H}$ NMR $(400 \mathrm{MHz}, \delta$ from TMS (ppm), $\mathrm{CDCl}_{3}$ ): $\delta$ 0.73-0.96, 1.23-1.42, 1.85-1.97, 2.17-2.64, 2.98, 4.13, 6.06-6.39, 6.73. GPC measurement evaluated that the number average molecular weight $\left(M_{\mathrm{n}}\right)$ is 900 , the weight average molecular weight $\left(M_{\mathrm{w}}\right)$ is 1600 , polydispersity $\left(M_{\mathrm{w}} / M_{\mathrm{n}}\right)$ is 1.72 . This result indicates that the resultant is an oligomer with molecular weight dispersion (Figure 1). Employment of EDOT as an arylene unit can be expected to avoid side reaction at $\beta$ and $\beta^{\prime}$ positions in the oxidative polycondensation because these parts are protected by the ethylenedioxy group.

Figure 1. GPC curve of ME1.

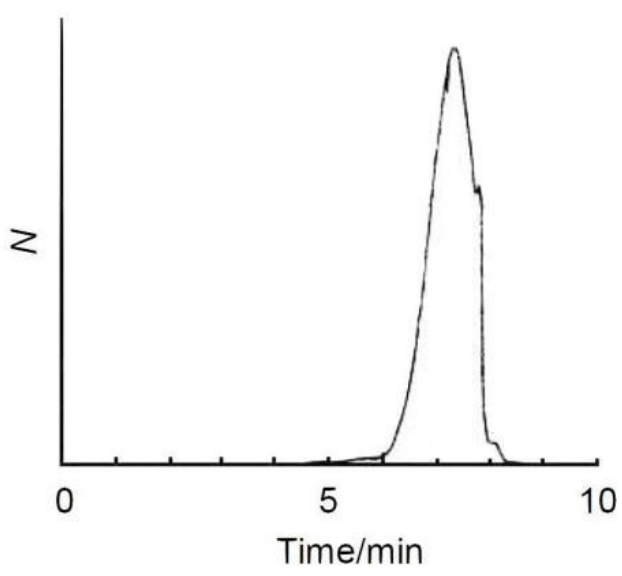

\section{Results and Discussion}

IR absorption spectra of (-)-myrtenal and ME1 are examined, as shown in Figure 2. An absorption band of $\mathrm{C}-\mathrm{H}$ stretching vibration of the aldehyde group of (-)-myrtenal is observed at around $1700 \mathrm{~cm}^{-1}$. On the other hand, IR absorption spectrum of ME1 shows no signals at around $1700 \mathrm{~cm}^{-1}$. The absence of the aldehyde signal in the IR absorption spectrum of ME1 indicates completion of the polycondensation reaction [34,35]. Characteristic absorption bands at $1089 \mathrm{~cm}^{-1}$ and $1360-1490 \mathrm{~cm}^{-1}$ 
of ME1 are attributable to $\mathrm{C}-\mathrm{O}-\mathrm{C}$ asymmetric stretching vibration and $\mathrm{C}=\mathrm{C}$ stretching vibration of EDOT, respectively. ${ }^{1} \mathrm{H}$ NMR measurements of ME1 and (-)-myrtenal were also performed for verification of completion of the reaction. NMR signals of ME1 were totally broadened. Typical signal at 9-10 ppm attributed to aldehyde group disappears after the reaction. This can be due to the fact that the polycondensation between the aldehyde group and arylene units was successfully carried out. The characteristic signals of EDOT (4.16 ppm, $-\mathrm{O}-\mathrm{CH}_{2}-\mathrm{CH}_{2}-\mathrm{O}-$ ) and (-)-myrtenal (0.7-2.9 ppm, each alkyl group) were observed in ME1 spectrum except aldehyde signal [36]. This result agrees with the IR measurements.

Figure 2. IR spectra of ME1 and (-)-myrtenal.

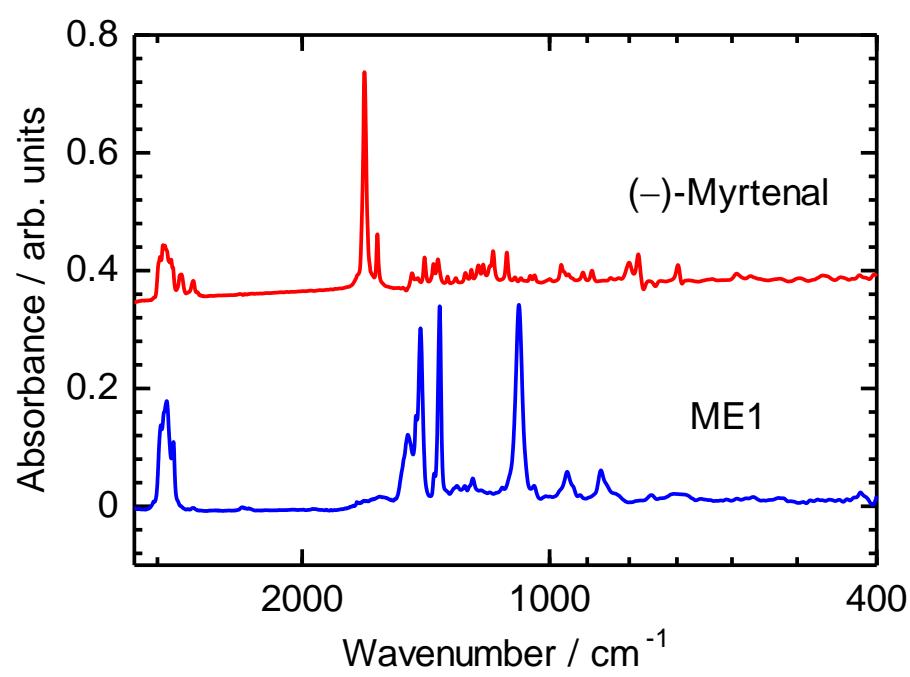

Figure 3. $\mathrm{CD}$ spectra of $\mathrm{ME} 1$ and (-)-myrtenal in $\mathrm{CHCl}_{3}$ solution.

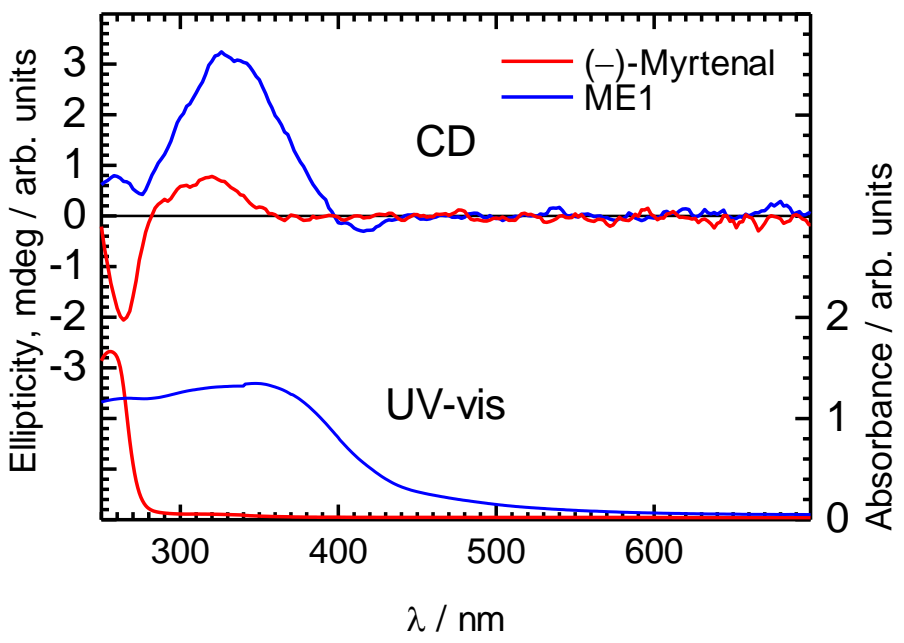

UV-vis absorption measurements of (-)-myrtenal and $\mathrm{ME} 1$ in $\mathrm{CHCl}_{3}$ were examined (Figure 3). A broad absorption band of ME1 indicates that the $\pi$-conjugation length of the backbone is developed. An optical bandgap of ME1 calculated from the absorption spectrum is to be $2.8 \mathrm{eV}$. Therefore, ME1 is considered to be a semiconducting organic material. Although the previously reported methine type polymers exhibited extended $\pi$-conjugation and low-bandgap because of benzenoid and quinonoid alternating structure in the main chain, the bandgap value in the present study is relatively large [28,37]. 
This is mainly because of the low degree of the polycondensation. Besides, bulky (-)-myrtenal moieties in the side chain might decrease the coplanarity of the main chain.

$\mathrm{CD}$ absorption spectra of ME1 and (-)-myrtenal were obtained in $\mathrm{CHCl}_{3}$ solution, as shown in Figure 3. Both spectra show clear CD curves. Broad CD signal of ME1 indicates that the backbone of ME1 individually shows chiroptical activity. After the polycondensation, chiroptical activity of the side chain remains and it induces chiroptical activity for the entire system. Such oxidative polycondensation can be simple and convenient method to introduce chiroptical activity for conjugated materials. We examined a doping effect of iodine (electron acceptor) for ME1 with UV-vis optical absorption, CD, and ESR. Figure 4 shows $\mathrm{CD}$ and $\mathrm{UV}$-vis absorption spectra of $\mathrm{ME} 1$ in $\mathrm{CHCl}_{3}$ with various iodine doping levels in solution. As for UV-vis spectra, clear changes in UV-vis absorption spectrum of ME1 were observed upon progress of the doping. New absorption peaks at $295 \mathrm{~nm}$ and $355 \mathrm{~nm}$ appeared with progress of the iodine doping. These two peaks indicate an occurrence of oxidation of ME1 by the doping. Furthermore, broad absorption band at 600-800 nm appeared gradually. This suggests generation of radical cations (charge species, polarons) for ME1 [38]. CD spectra of ME1 by the iodine doping show blue shift at short wavelengths and decrease of the intensities by the iodine doping. The blue shift implies that the short helical form induced by the chiral substituent is released by the doping. Color change of ME1 in solution with various iodine doping levels is shown in Figure 5. Original color of iodine in a solution is purple. However, addition of iodine leads changes in color for the material from orange to dark green. This result suggests that the iodine doping tunes the color and chiroptical activity of ME1. Commission Internationale de l'Eclairage (International Commission on Illumination, CIE) color space confirms the color in the solution, as shown in Figure 6.

Figure 4. $\mathrm{CD}$ and $\mathrm{UV}$-vis absorption spectra of $\mathrm{ME} 1$ in $\mathrm{CHCl}_{3}$ with various iodine doping levels.

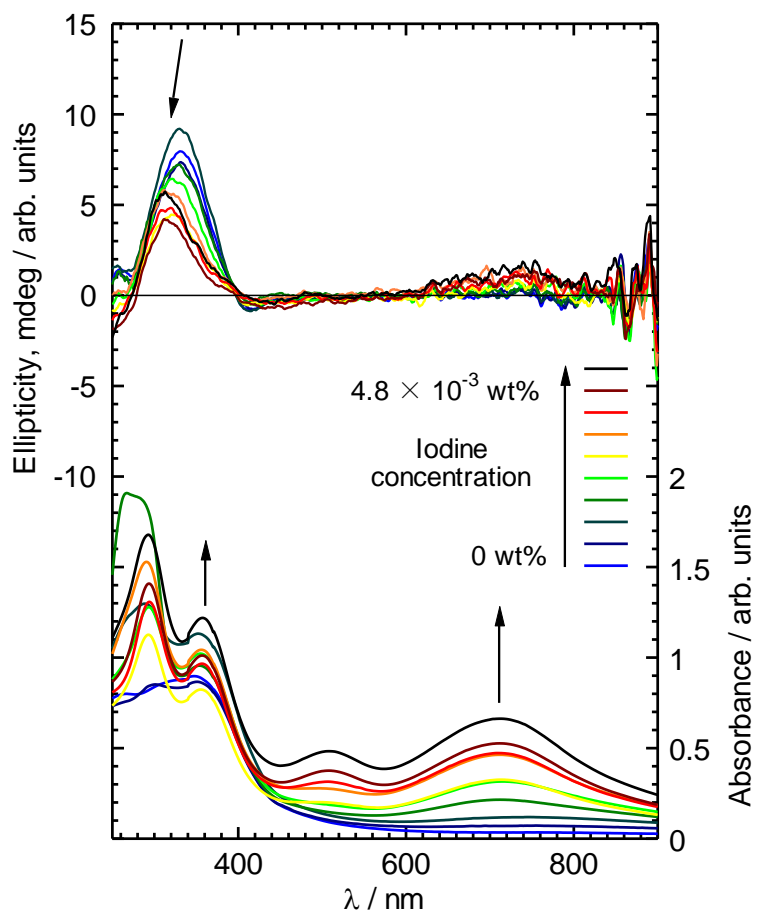


Figure 5. Color change of $\mathrm{ME} 1$ in $\mathrm{CHCl}_{3}$ solution from orange to green with iodine doping.

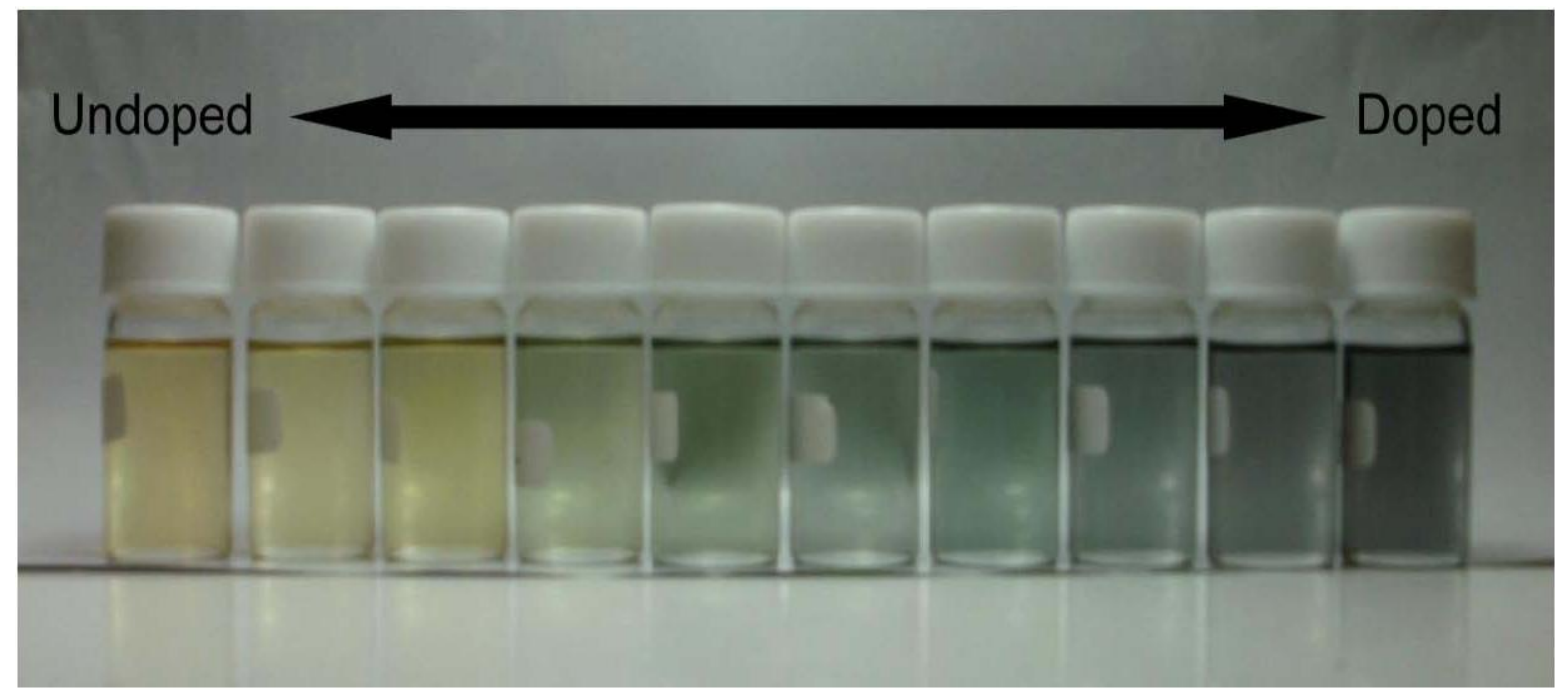

Figure 6. Change in CIE color space coordination diagram of ME1 with iodine doping.

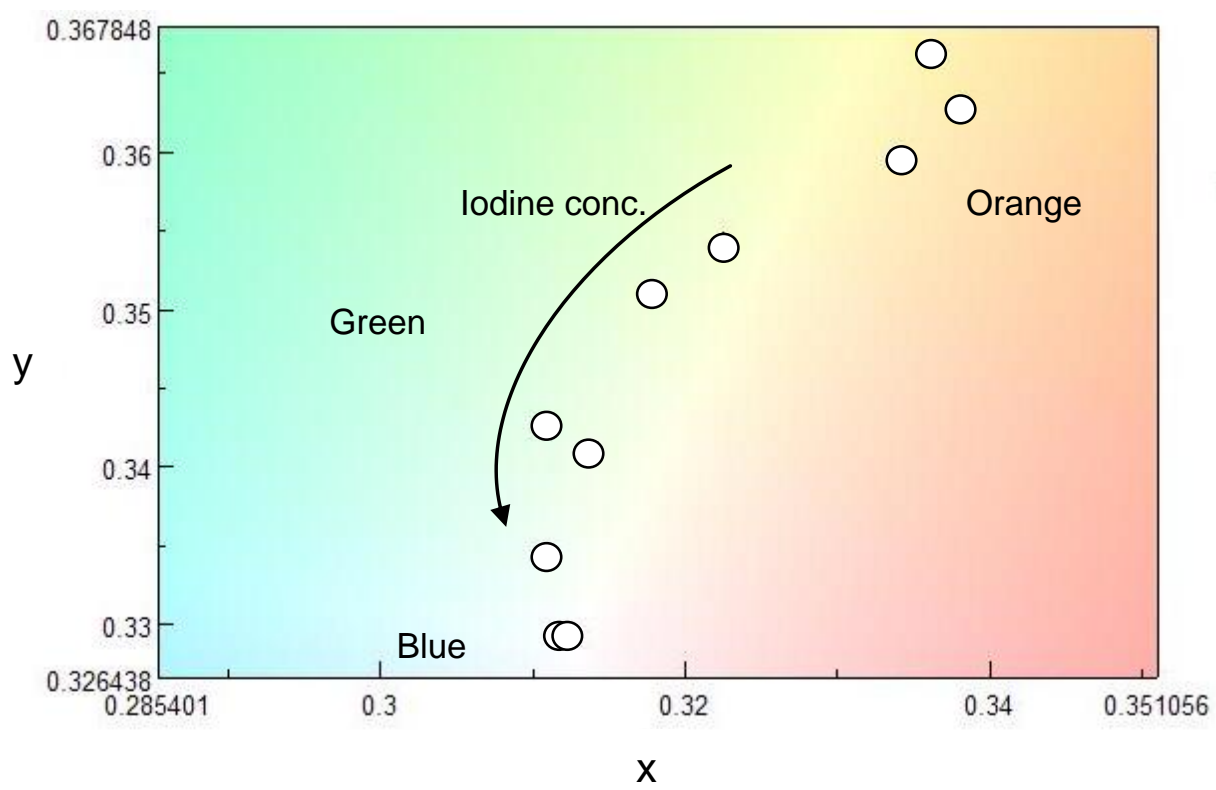

In-situ ESR spectra of ME1 with vapor phase iodine doping were measured (Figure 7). As prepared oligomer shows weak ESR signal, indicating incomplete dedoping of $\mathrm{POCl}_{3}$ with aqueous ammonia treatment, or doping with oxygen in the air. The spin concentration increased rapidly upon the doping. This indicates a generation of radical cations along the main chain. Figure 8 shows $g$-value, intensity, and peak width $\left(\Delta H_{\mathrm{pp}}\right)$ plots $v s$. the doping time. The peak width and $g$-value are constant upon the doping. However, the intensity is increased by the doping, indicating that the doping is effectively carried out and charge species are generated along the main chain [39]. 
Figure 7. In-situ ESR spectra during vapor phase iodine doping.

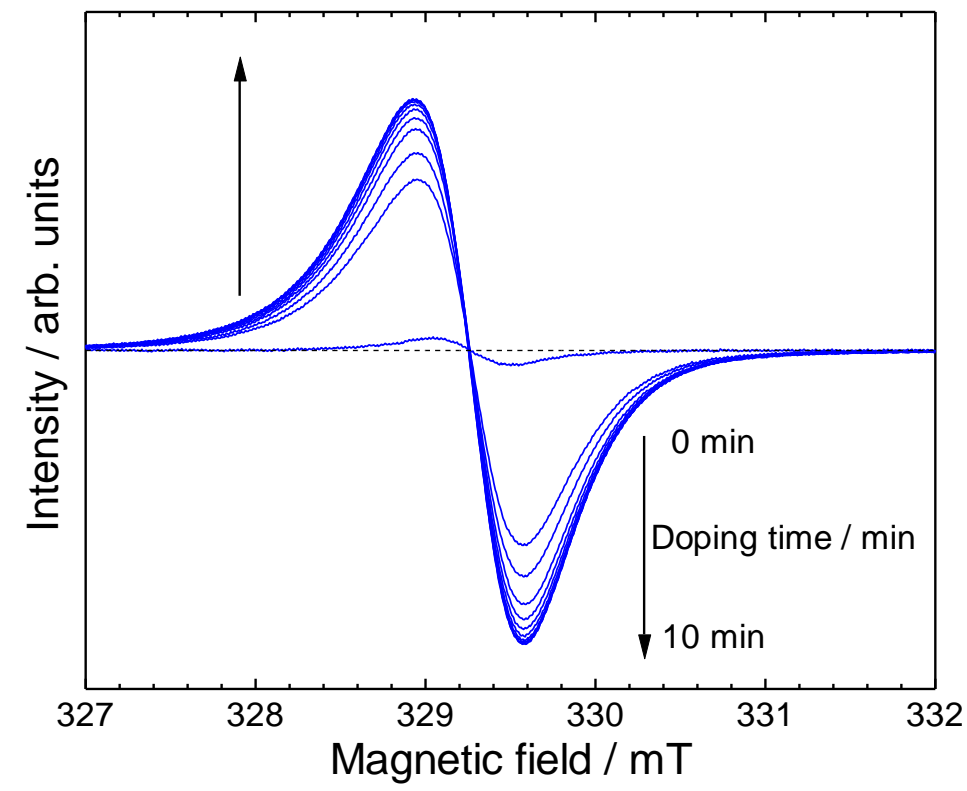

Figure 8. $g$-value, intensity, and peak width $\left(\Delta H_{\mathrm{pp}}\right)$ of ME1 with vapor phase iodine doping for $0-10 \mathrm{~min}$.

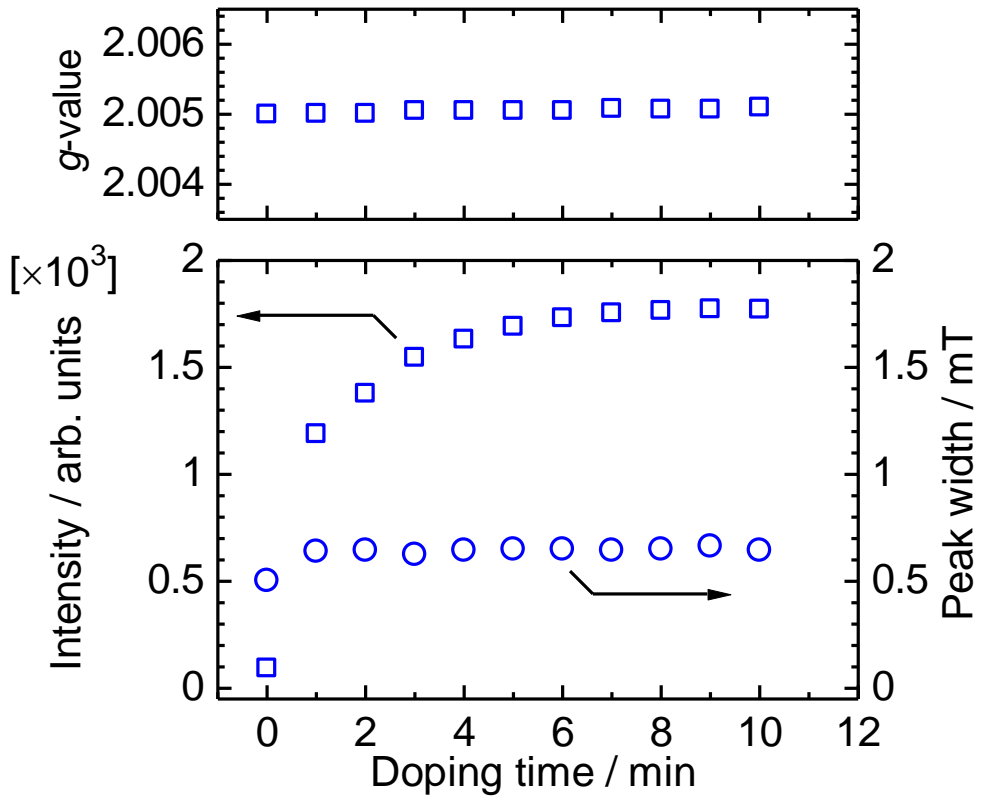

\section{Conclusions}

A new methine $\pi$-conjugated oligomer was synthesized from EDOT and (-)-myrtenal. This shows a broad absorption band and a CD signal in the long wavelengths. The chiral side chain induces helical conformation of the main chain to exhibit chiroptical activity. Iodine doping for the oligomer was examined, and the doped state was monitored with the UV-vis optical absorption, the CD, and the ESR spectroscopy. The UV-vis absorption and the ESR measurements confirm the formation of radical cations. CD spectra of the oligomer show blue shift of the CD signal during the doping. This suggests that the change in electronic structure upon doping tunes its chiroptical activity. 


\section{Acknowledgements}

The author would like to thank Glass work shop of Central Workshop of University of Tsukuba for fine glass works.

\section{References}

1. Nikolou, M.; Dyer, A.L.; Steckler, T.T.; Donoghue, E.P.; Wu, Z.; Heston, N.C.; Rinzler, A.G.; Tanner, D.B.; Reynolds, J.R. Dual $n$ - and $p$-type dopable electrochromic devices employing transparent carbon nanotube electrodes. Chem. Mater. 2009, 21, 5539-5547.

2. Kumar, A.; Bokria, J.G.; Buyukmumcu, Z.; Dey, T.; Sotzing, G.A. Poly(thieno[3,4-b]furan), a new low band gap polymer: Experiment and theory. Macromolecules 2008, 41, 7098-7108.

3. Zerza, G.; Röthler, B.; Sariciftci, N.S.; Gómez, R.; Segura, J.L.; Martín, N. Photophysical properties and optoelectronic device applications of a novel naphthalene-vinylene type conjugated polymer. J. Phys. Chem. B 2001, 105, 4099-4104.

4. Pei, J.; Yu, W.-L.; Huang, W.; Heeger, A.J. A novel series of efficient thiophene-based light-emitting conjugated polymers and application in polymer light-emitting diodes. Macromolecules 2000, 33, 2462-2471.

5. Rathnayake, H.P.; Cirpan, A.; Lahti, P.M.; Karasz, F.E. Optimizing LED Properties of 2,7-Bis(phenylethenyl)fluorenes. Chem. Mater. 2006, 18, 560-566.

6. Crouch, D.J.; Skabara, P.J.; Lohr, J.E.; McDouall, J.J.W.; Heeney, M.; McCulloch, I.; Sparrowe, D.; Shkunov, M.; Coles, S.J.; Horton, P.N.; Hursthouse, M.B. Thiophene and selenophene copolymers incorporating fluorinated phenylene units in the main chain: Synthesis, characterization, and application in organic field-effect transistors. Chem. Mater. 2005, 17, 6567-6578.

7. Tang, M.L.; Reichardt, A.D.; Wei, P.; Bao, Z. Correlating carrier type with frontier molecular orbital energy levels in organic thin film transistors of functionalized acene derivatives. $J$. Am. Chem. Soc. 2009, 131, 5264-5273.

8. Yang, M.; Peng, B.; Liu, B.; Zou, Y.; Zhou, K.; He, Y.; Pan, C.; Li, Y. Synthesis and photovoltaic properties of copolymers from Benzodithiophene and Thiazole. J. Phys. Chem. C 2010, 114, 17989-17994.

9. Kim, J.Y.; Qin, Y.; Stevens, D.M.; Kalihari, V.; Hillmyer, M.A.; Frisbie, C.D. High open-circuit voltage photovoltaic cells with a low bandgap copolymer of Isothianaphthene, Thiophene, and Benzothiadiazole units. J. Phys. Chem. C 2009, 113, 21928-21936.

10. Zhen, F.Z.; Eshbaugh, A.A.; Schanze, K.S. Low-bandgap donor-acceptor conjugated polymer sensitizers for dye-sensitized solar cells. J. Am. Chem. Soc. 2011, 133, 3063-3069.

11. Hou, J.; Park, M.-H.; Zhang, S.; Yao, Y.; Chen, L.-M.; Li, J.-H.; Yang, Y. Bandgap and molecular energy level control of conjugated polymer photovoltaic materials based on Benzo[1,2-b:4,5- $\left.b^{\prime}\right]$ dithiophene. Macromolecules 2008, 41, 6012-6018.

12. Huang, X.; Shi, Q.; Chen, W.-Q.; Zhu, C.; Zhou, W.; Zhao Z.; Duan, X.-M.; Zhan, X. Low-bandgap conjugated donor-acceptor copolymers based on porphyrin with strong two-photon absorption. Macromolecules 2010, 43, 9620-9626. 
13. Zou, Y.; Gendron, D.; Neagu-Plesu, R.; Leclerc, M. Synthesis and characterization of new low-bandgap diketopyrrolopyrrole-based copolymers. Macromolecules 2009, 42, 6361-6365.

14. Kiebooms, R.H.L.; Adriaensens, P.J.A.; Vanderzande, D.J.M.; Gelan, J.M.J.V. Grignard reactions on Ortho DicarboxylicArene derivatives. Synthesis of 1,3-Dithienylisothianaphthene compounds. J. Org. Chem. 1997, 62, 1473-1480.

15. Groenendaal, L.B.; Jonas, F.; Freitag, D.; Pielartzik, H.; Reynolds, J.R. Poly(3,4-ethylenedioxythiophene) and its derivatives: Past, present, and future. Adv. Mater. 2000, 12, 481-494.

16. Roncali, J.; Blanchard, P.; Frère, P. 3,4-Ethylenedioxythiophene (EDOT) as a versatile building block for advanced functional $\pi$-conjugated systems. J. Mater. Chem. 2005, 15, 1589-1610.

17. Segura, J.L.; Gómez, R.; Blanco, R.; Reinold, E.; Bäuerle, P. Synthesis and electronic properties of Anthraquinone-, Tetracyanoanthraquinodimethane-, and Perylenetetracarboxylic Diimide-functionalized Poly(3,4-ethylenedioxythiophenes). Chem. Mater. 2006, 18, 2834-2847.

18. Han, D.-H.; Kim, J.-W.; Park, S.-M. Electrochemistry of conductive polymers 38. Electrodeposited poly(3,4-ethylenedioxy-thiophene) studied by current sensing atomic force microscopy. J. Phys. Chem. B 2006, 110, 14874-14880.

19. Chahma, M.; Myles, D.J.T.; Hicks, R.G. Synthesis and electropolymerization behavior of bis (Oligothienyl) sulfides. Generation of heteroaromatic Poly(p-phenylene sulfide) analogs. Chem. Mater. 2005, 17, 2672-2678.

20. Pai, C.-L.; Liu, C.-L.; Chen, W.-C.; Jenekhe, S.A. Electronic structure and properties of alternating donor-acceptor conjugated copolymers: 3,4-Ethylenedioxythiophene (EDOT) copolymers and model compounds. Polymer 2006, 47, 699-708.

21. Jenekhe, S.A. Synthesis and characterization of carbon atom bridged heterocyclic polymers of specified conjugation length. 1. Novel polyterthiophenes. Macromolecules 1990, 23, 2848-2854.

22. Chen, W.-C.; Liu, C.-L.; Yen, C.-T.; Tsai, F.-C.; Tonzola, C.J.; Olson, N.; Jenekhe, S.A. Theoretical and experimental characterization of small band gap poly(3,4-ethylenedioxythiophene methine)s. Macromolecules 2004, 37, 5959-5964.

23. Chen, W.-C.; Jenekhe, S.A. New polyaniline derivatives: Poly(4,4'-diphenylamine methylenes) and Poly(4,4'-diphenylimine methines). Macromolecules 1992, 25, 5919-5926.

24. Tsukamoto, N.; Ha, J.; Sato, H.; Strzelec, K. Chemical doping of Triphenylaminebenzaldehyde polymers. Int. J. Polym. Mater. 2004, 53, 799-807.

25. Toussaint, J.M.; Brédas, J.L. Theoretical analysis of the geometric and electronic structure of small-band-gap polythiophenes: Poly(5,5'-bithiophene methine) and its derivatives. Macromolecules 1993, 26, 5240-5248.

26. Stagnaro, P.; Pioli, F.; Panizza, M.; Gandini, A. Acid-catalyzed polycondensation of 2-acetoxymethyl-3,4-dimethylthiophene. Access to a novel poly(thienylenemethine) with alternating aromatic- and quinoid-like structures. Macromolecules 2009, 42, 2455-2461.

27. Kiebooms, R.; Wudl, F. Synthesis and characterisation of poly(isothianaphthenemethine). Synth. Met. 1999, 101, 40-43.

28. Chen, W.C.; Jenekhe, S.A. Small bandgap conducting polymers based on conjugated poly(heteroarylene methine). 1 Precursor poly(heteroarylene methylenes). Macromolecules 1995, $28,454-464$. 
29. Chen, W.C.; Jenekhe, S.A. Small bandgap conducting polymers based on conjugated poly(heteroarylene methines). 2. Synthesis, structure, and properties. Macromolecules 1995, 28, 465-480.

30. Caesar, P.D.; Sachanen, A.N. Thiophene-formaldehyde condensation. Ind. Eng. Chem. 1948, 40, 922-928.

31. Aota, H.; Itai, Y.; Matsumoto, A.; Kamachi, M. Synthesis of $\pi$-conjugated polymer containing porphyrins. Chem. Lett. 1994, 1994, 2043-2046.

32. Rothemund, P. Formation of porphyrines from pyrrole and aldehydes. J. Am. Chem. Soc. 1935, 57, 2010-2011.

33. Rothemund, P. A new porphyrin synthesis. The synthesis of porphin. J. Am. Chem. Soc. 1936, 58, 625-627.

34. Goto, H.; Akagi, K. Synthesis of a pyrrole-based methine bridge type liquid-crystalline conjugated polymer. J. Polym. Sci. A Polym. Chem. 2005, 43, 616-629.

35. Meng, L.-J.; Wu, H.-C.; Gao, C.; Yi, W.-H. Synthesis and characterization of a kind of poly(3-butylthiophene methine) with Azo side groups. J. Appl. Polym. Sci. 2005, 97, 1261-1265.

36. Multiplet signals at 6.0-6.5 ppm of ME1 were observed in the ${ }^{1} \mathrm{H}$ NMR measurement. Although side reactions at the side chain might occur during the polycondensation process, the signals can be related with molecular weight dispersity.

37. Zaman, M.B.; Perepichka, D.F. A new simple synthesis of poly(thiophene-methine)s. Chem. Commun. 2005, 33, 4187-4189.

38. Neugebauer, H.; Kvarnström, C.; Brabec, C.; Sariciftci, N.S.; Kiebooms, R.; Wudl, F.; Luzzati, S. Infrared spectroelectrochemical investigations on the doping of soluble Polyisothianaphthene Methine (PIM). J. Chem. Phys. 1999, 110, 12108-12115.

39. Patil, A.O.; Heeger, A.J.; Wudl, F. Optical properties of conducting polymers. Chem. Rev. 1988, $88,183-200$.

(C) 2011 by the authors; licensee MDPI, Basel, Switzerland. This article is an open access article distributed under the terms and conditions of the Creative Commons Attribution license (http://creativecommons.org/licenses/by/3.0/). 